\title{
The grey zone of physicians: Negative T waves on ECG's precordial leads
}

\author{
Massimo Bolognesi* \\ Department of Internal General Medicine, General Practitioner - ASL 112 Cesena Via Ungaretti 49447521 Cesena, Italy
}

\begin{abstract}
T wave inversions on electrocardiogram (ECG) can manifest from any process that result in a relative delay in regional ventricular repolarization. A variety of clinical syndromes can cause $\mathrm{T}$-wave inversions, ranging from life-threatening events to entirely benign conditions. The differential diagnosis of precordial $\mathrm{T}$ wave inversion leads is not always straightforward and can represent the grey zone for cardiologists. Here the author describes the case of an otherwise healthy $84-$ year-old gentleman who presented to a cardiologist with an ECG that showed a normal sinus rhythm with $\mathrm{T}$ wave inversions across the anterolateral precordial leads of uncertain nature. Subsequent examinations by his general practitioner, such as exercise stress testing and echocardiography, showed inducible silent myocardial ischemia and the presence of left ventricular organized apical thrombus. The present case delineates the importance of recognizing this ECG pattern and, in the correct clinical setting, can facilitate the diagnosis and treatment of a relatively common medical condition.
\end{abstract}

\section{Introduction}

Several different clinical entities present with inverted $\mathrm{T}$ waves on electrocardiogram in clinical setting, ranging from life-threatening events to entirely benign conditions. Jacobson and Schrire were the first to described the differential diagnosis of inverted T-wave that included various pathologies, such as ischemic heart disease, bradyarrhythmia, right ventricular hypertrophy, conduction disorders, metabolic disturbances, changes during diagnostic coronary angiography and acute cerebral disease [1].

Other clinical situations are added including acute adrenergic stress (Takotsubo cardiomyopathy) [2,3], pulmonary edema [4,5], antiarrhythmic drug effects [6], pulmonary embolism [7], cardiac memory secondary to transient tachycardia [8], post ventricular pacing states [9], idiopathic [10] and in relation to cocaine use [11]. Recently, reversible or permanent inverted T-waves were found in $38 \%$ of patients with congenital coronary artery-ventricular multiple micro-fistulas (MMFs) [12]. Literature also reported that transient T-wave inversion may occur in numerous conditions such as acute coronary syndrome [13], cardiac memory T-wave [14], subarachnoid hemorrhage [15], electroconvulsive therapy [16], and indeterminate origin [17]. Chronic T-wave inversion may accompany a cardiomyopathy such as apical hypertrophic cardiomyopathy [18] and arrhythmogenic right ventricular cardiomyopathy/dysplasia [19]. The definite diagnosis in the presence of inverted T-wave can be assessed by meticulous family history of sudden cardiac death or arrhythmias, by physical examination as well as appropriate non-invasive, semi-invasive or invasive diagnostic investigations. Here the author describes a case report, which focuses on T-wave inversion showing on the precordial anterolateral leads in an otherwise healthy 84-year-old gentleman and discuss its differential diagnosis in clinical setting with emphasis on the misdiagnosis of coronary artery disease.

\section{Case report}

This report describes the clinical case of an 84-year-old gentleman who has occasionally been followed by cardiologists of our local hospital having been an amateur athlete. In the last 7 years this asymptomatic gentleman has always presented significant electrocardiographic abnormalities of ventricular repolarization, particularly inverted $\mathrm{T}$ waves on precordial anterolateral leads, i.e. $\mathrm{I}-\mathrm{aVL}-\mathrm{V}_{4}-\mathrm{V}_{5}-\mathrm{V}_{6}$ (Figure 1). Several years ago due to this evidence a myocardial scintigraphy was performed with negative results for perfusion defects.

Therefore, the asymptomatic patient made no further investigation, because the clinical interpretation was that the patient had chronic T-wave inverted due to left ventricular hypertrophy. However, this man recently has come to our attention with a resting ECG that showed

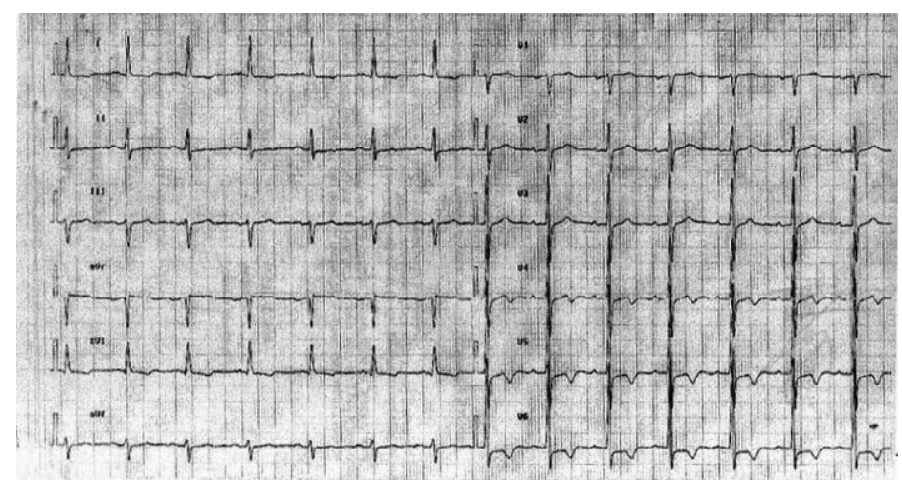

Figure 1. Resting ECG shows inverted $T$ waves on anterolateral leads $\left(D_{1}-a V L-V_{4}-\right.$ $\left.\mathrm{V}_{5}-\mathrm{V}_{6}\right)$.

Correspondence to: Massimo Bolognesi, Department of Internal General Medicine, General Practitioner - ASL 112 Cesena Via Ungaretti 49447521 Cesena, Italy, Tel: +390547645074; E-mail: massimo.bolognesi@gmail.com

Key words: grey zone, inverted T waves, cardiologist, ischemic heart disease

Received: June 18, 2015; Accepted: July 11, 2015; Published: July 15, 2015 


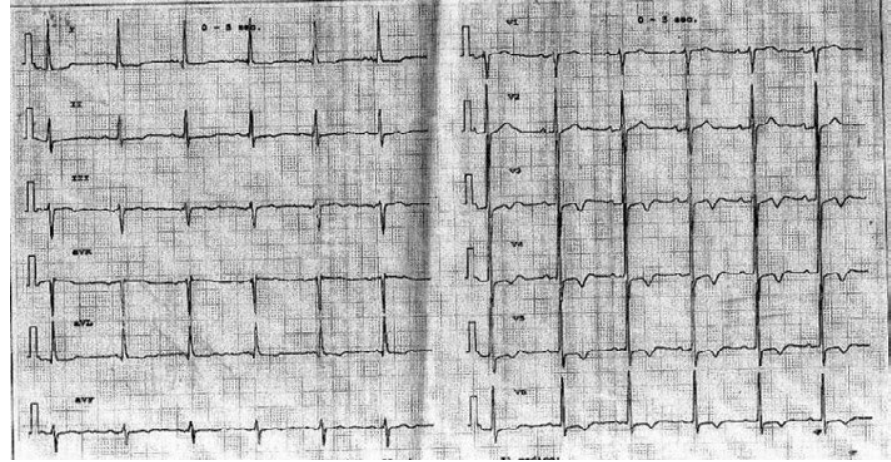

Figure 2. Resting ECG shows inverted $T$ waves on anterolateral leads $\left(\mathrm{D}_{1}-\mathrm{aVL}-\mathrm{V}_{3}-\mathrm{V}_{4}-\right.$ $\left.\mathrm{V}_{5}-\mathrm{V}_{6}\right)$.

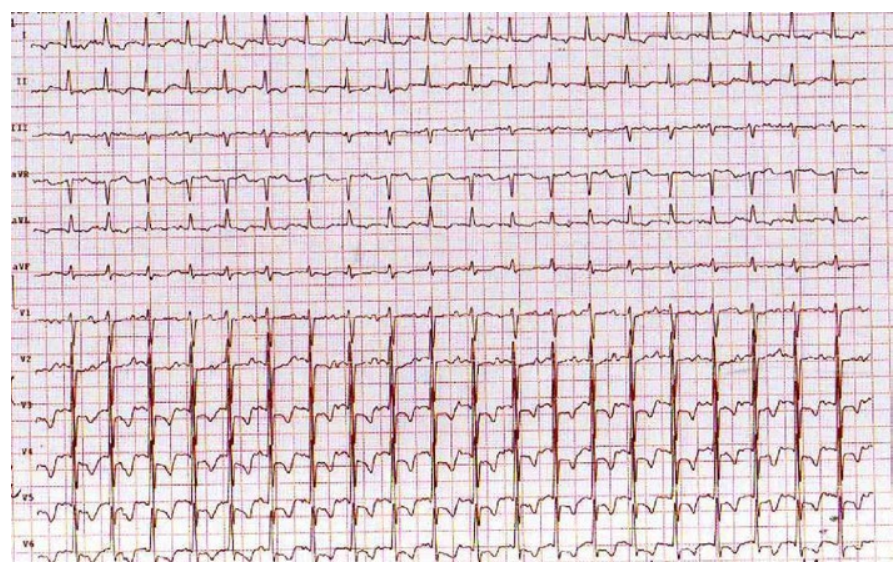

Figure 3. Exercise ECG stress test shows ST-segment depression on anterolateral leads.

a slight worsening of the ventricular repolarization abnormalities, i.e, the presence of inverted $\mathrm{T}$ waves, deeper, and symmetrical peak, extending through to the lead $\mathrm{V}_{3}$. (Figure 2). Referred to hospital for a coronary angiography, this gentleman was sent back home. It was stated that the negative $\mathrm{T}$ waves were secondary and not primary abnormalities of ventricular repolarization (VR) likely caused by a left ventricular hypertrophy (LVH), although this patient had never suffered from high blood pressure and there were no signs of valvular disease, apart from a note of mild mitral regurgitation. Subsequently, the same interpretation of secondary abnormalities of the VR due to a probable LVH was confirmed. At this point the author decided to refer the patient to a cycle ergometer exercise test that was markedly positive for inducible subendocardial ischemia at low workload (Figure 3). This is evident from the marked morphology of the ST segment depression with down sloping pattern on the anterolateral ECG leads. A subsequent two-dimensional transthoracic (2D TT) echocardiographic examination showed the presence of akinesia of the apical segment of the anterolateral wall, with a surprising presence of an organized thrombus of apex (Figure 4). Following suitable anticoagulation therapy the patient was subjected to diagnostic and interventional coronary angiography which provided to solve with angioplasty and stent placement the significant stenosis of the proximal circumflex coronary artery. Three days later the patient was discharged in good general conditions.

\section{Discussion}

The natural history of patients with inverted $\mathrm{T}$ waves is variable
Left Ventricular Apical Thrombus

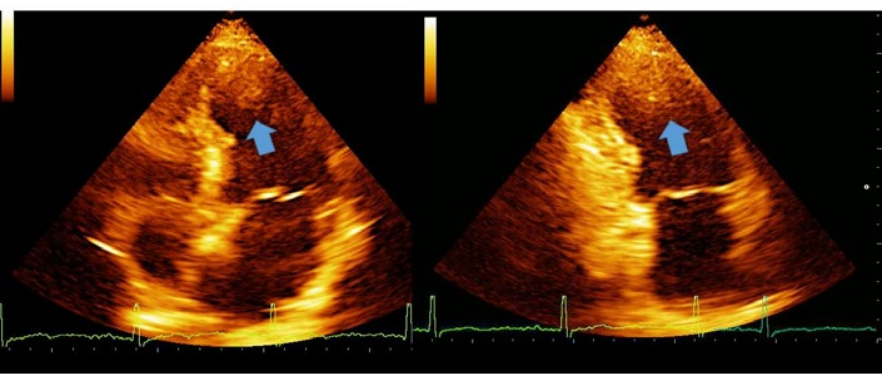

Figure 4. 2D Trans Thoracic echocardiography shows apical thrombus.

[20], ranging from a normal finding without pathologic issues to clinical situations causing sudden death related to cardiac or respiratory syndromes. The T wave is normally upright in leads I, II, and V2 to V6; inverted in lead aVR; and variable in leads III, aVL, aVF, and V1. In general, an inverted $\mathrm{T}$ wave in a single lead in one anatomic segment (i.e., inferior, lateral, or anterior) is unlikely to represent acute pathology; for instance, a single inverted T wave in either lead III or aVF can be a normal variant. The causes of T-wave inversions comprise two categories: primary $\mathrm{T}$-wave changes and secondary $\mathrm{T}$-wave changes [21]. Alterations in the duration or morphology of the potential action, without concurrent changes in the orderly sequence of activation, are termed "primary changes." Primary T-wave inversions are associated with benign syndromes, such as the persistent juvenile T-wave pattern, as well as morbid conditions, including acute coronary ischemic events and cerebral nervous system catastrophe. Secondary T-wave changes result from aberrant ventricular activation in the context of normal characteristics of potential action; examples include bundle-branch blocks, ventricular pre-excitation states, ventricular ectopic beats, and left ventricular hypertrophy. In elderly patients T-wave inversions are most probably associated with coronary artery disease, as seen in myocardial ischemia [22]. In general, inverted $\mathrm{T}$ waves related to acute coronary syndrome are symmetric in shape [23]. An important subgroup of patients with pre-infarction angina can present with significantly abnormal T-wave inversions-either symmetric, deeply inverted $\mathrm{T}$ waves or biphasic $\mathrm{T}$ waves in the precordial leads (V1, V2, and V3 in particular) [24].

Furthermore, patients with old myocardial infarction can have persistent $\mathrm{T}$-wave inversions as a manifestation of the myocardial ischemia. As mentioned above a variety of clinical syndromes can cause T-wave inversions, ranging from life-threatening events, such as acute coronary ischemia, pulmonary embolism, and CNS injury, to entirely benign conditions, such as normal variant $\mathrm{T}$ - wave inversions and the persistent juvenile T-wave inversion. In patients with $\mathrm{LVH}$, ST-segment/T-wave changes are encountered in approximately $70 \%$ of cases, including ST-segment deviations and abnormal T waves [25]. Of these findings, the T wave can be inverted and is most often seen in leads with large positive QRS complexes, such as leads I, aVL, $\mathrm{V}_{5}$, and $\mathrm{V}_{6}$ but these inverted $\mathrm{T}$ waves have a gradual downsloping limb with a rapid return to the baseline [26]. These abnormalities are related to the LVH pattern and are not suggestive of ischemic heart disease. This report is emblematic because it shows how easy it is to erroneously judge the conditions of an elderly and asymptomatic patient who present chronic negative T waves. As it can be seen from the ECG's tracing left axis deviation is not present and the complex QTS is tight. Therefore, it is certainly not appropriate to consider the inverted $\mathrm{T}$ waves with anomalies of the ventricular repolarization as secondary 
rather than primary. These ECG findings are typical of ischemic heart disease. A flat/negative $\mathrm{T}$ wave may be seen for years as a residual pattern in chronic ischemic heart disease with or without Q-wave myocardial infarction. Furthermore, the clinical history and the age of the patient were to exclude the causes of congenital and acquired left ventricular hypertrophy, so that it was quite obvious that the solution was to be found in an examination able to evoke the presence of inducible myocardial ischemia. The first test to be performed in these cases is always the exercise test, and then, if necessary, a myocardial scintigraphy and pharmacological stress echocardiography. The diagnosis based solely on the morphology of the T-wave, ie the symmetry shape and depth, in the absence of signs of overload of the left ventricle is often misleading, and not considering the extension of the anomalies even in the front-lead, and particularly in $\mathrm{V}_{3}$, as a sign of a probable myocardial ischemia, is a clear mistake.

\section{Conclusion}

This case highlights the ontogeny of error in medicine when a clinical diagnosis is made for the following reasons:

\section{1) A previous diagnosis is considered right;}

2) Electrocardiograms might not be examined carefully, and recent changes may go undetected;

3) The patient's conditions are at times erroneously judged only on the basis of lack of symptoms;

4) Appropriate further examinations, which are able to quickly clarify doubts, are not required;

5) The possibility of significant coronary artery disease is totally excluded in the presence of a good left ventricular systolic function.

Silent myocardial ischemia is a subtle and mysterious disease that should not be underestimated, especially in the presence of negative $\mathrm{T}$ waves of uncertain significance on anterolateral leads in elderly asymptomatic patients. A critical evaluation should be made and appropriate solutions found for better analysis.

\section{Competing interests}

The author declare that no has competing interests

\section{References}

1. Jacobson D, Schrire V (1966) Giant T wave inversion. Br Heart $J$ 28: 768-775. [Crossref]

2. Tsuchihashi K, Ueshima K, Uchida T, Oh-mura N, Kimura K, et al. (2001) Transient left ventricular apical ballooning without coronary artery stenosis: a novel heart syndrome mimicking acute myocardial infarction. Angina Pectoris-Myocardial Infarction Investigations in Japan. J Am Coll Cardiol 38: 11-18 [Crossref]

3. Wittstein IS, Thiemann DR, Lima JA, Baughman KL, Schulman SP, et al. (2005) Neurohumoral features of myocardial stunning due to sudden emotional stress. $N$ Engl $J$ Med 352: 539-548. [Crossref]

4. Littmann L (1999) Large T wave inversion and QT prolongation associated with pulmonary edema: a report of nine cases. J Am Coll Cardiol 34: 1106-1110. [Crossref]
5. Pascale P, Quartenoud B, Stauffer JC (2007) Isolated large inverted T wave in pulmonary edema due to hypertensive crisis: a novel electrocardiographic phenomenon mimicking ischemia? Clin Res Cardiol 96: 288-294. [Crossref]

6. Said SA, Somer ST, Oude Luttikhuis HA (1994) Flecainide-induced JT prolongation, $\mathrm{T}$ wave inversion and ventricular tachycardia during treatment for symptomatic atrial fibrillation. Int J Cardiol 44: 285-287. [Crossref]

7. Pillarisetti J, Gupta K (2010) Giant Inverted T waves in the emergency department: case report and review of differential diagnoses. J Electrocardiol 43: 40-42. [Crossref]

8. Hanna EB, Glancy DL (2011) ST-segment depression and T-wave inversion: classification, differential diagnosis, and caveats. Cleve Clin J Med 78: 404-414. [Crossref]

9. Littmann L, Fertman AF (2011) Large T-wave inversion in a patient with a pacemaker. Arch Intern Med 171: 1314. [Crossref]

10. Corbella F, Dragonetti L, Rivas C, Eyheremendy E, Acunzo R (2009) Giant negative T waves of indeterminate origin. Rev Argent Cardiol 2: 131-134.

11. Zimmerman FH, Gustafson GM, Kemp HG Jr (1987) Recurrent myocardial infarction associated with cocaine abuse in a young man with normal coronary arteries: evidence for coronary artery spasm culminating in thrombosis. J Am Coll Cardiol 9: 964-968. [Crossref]

12. Said SA, Schiphorst RH, Derksen R, Wagenaar L (2013) Coronary cameral fistulas in adults (first of two parts). World J Cardiol 5: 329-336. [Crossref]

13. Fisher M, Lichstein E, Hollander G, Greengart A, Shani J (1992) Giant T-wave inversion in patients with acute coronary insufficiency. Chest 101: 935-937. [Crossref]

14. Littmann L, Fertman AF (2011) Large T-wave inversion in a patient with a pacemaker. Arch Intern Med 171: 1314. [Crossref]

15. Chatterjee S (2011) ECG Changes in Subarachnoid Haemorrhage: A Synopsis. Neth Heart J 19: 31-34. [Crossref]

16. Narasimhan S (2008) Electroconvulsive therapy and electrocardiograph changes. $J$ Postgrad Med 54: 228-229. [Crossref]

17. Corbella F, Dragonetti L, Rivas C, Eyheremendy E, Acunzo R (2009) Giant negative T waves of indeterminate origin. Rev Argent Cardiol 2: 131-134.

18. Yusuf SW, Bathina JD, Banchs J, Mouhayar EN, Daher IN (2011) Apical hypertrophic cardiomyopathy. World J Cardiol 3: 256-259. [Crossref]

19. Marcus FI, McKenna WJ, Sherrill D, Basso C, Bauce B, et al. (2010) Diagnosis of arrhythmogenic right ventricular cardiomyopathy/dysplasia: proposed modification of the task force criteria. Circulation 121: 1533-1541. [Crossref]

20. Simon K, Hackett D, Szelier A, Szabó P, Szépvölgyi A, et al. (1994) The natural history of postischemic T-wave inversion: a predictor of poor short-term prognosis? Coron Artery Dis 5: 937-942. [Crossref]

21. Said SA, Bloo R, de Nooijer R, Slootweg A (2015) Cardiac and non-cardiac causes of T-wave inversion in the precordial leads in adult subjects: A Dutch case series and review of the literature. World J Cardiol 7: 86-100. [Crossref]

22. Ahto M, Isoaho R, Puolijoki H, Laippala P, Romo M, et al. (1998) Prevalence of coronary heart disease, associated manifestations and electrocardiographic findings in elderly Finns. Age Ageing 27: 729-737. [Crossref]

23. Bayes de Luna A, Fiol M (2008) Electrocardiography in Ischemic Heart Disease. Clinical and imaging correlations and prognostic implications. Blackwell-Futura, 2008.

24. Thygesen K, Alpert JS, White HD; Joint ESC/ACCF/AHA/WHF Task Force for the Redefinition of Myocardial Infarction (2007) Universal definition of myocardial infarction. J Am Coll Cardiol 50: 2173-2195. [Crossref]

25. Sheridan D (1998) Left Ventricular Hypertrophy. Churchill Livingstone, 1998.

26. Morrison I, Clark E, Macfarlane PW (2007) Evaluation of the electrocardiographic criteria for left ventricular hypertrophy. Anadolu Kardiyol Derg 7: 159-163. [Crossref]

Copyright: (C2015 Bolognesi M. This is an open-access article distributed under the terms of the Creative Commons Attribution License, which permits unrestricted use, distribution, and reproduction in any medium, provided the original author and source are credited. 